\title{
The effects of locational factors on vandalism in the seaside parks
}

\author{
Aysel Yavuz ${ }^{1 *}$ and Nilgün Kuloğlu ${ }^{2}$ \\ ${ }^{1}$ Department of Landscape, Faculty of Forestry, Karadeniz Technical University, Trabzon, Turkey 61080. \\ ${ }^{2}$ Department of Architecture, Faculty of Architecture, Karadeniz Technical University, Trabzon, Turkey 61080.
}

Accepted 22 August, 2011

\begin{abstract}
Urban open spaces are places located and designed within the context of urban and landscape design that gives people opportunities in the urban environment. The existence of open public spaces contributes to symbolic dimensions as well as urban physical and functional dimensions that city dweller use and benefit. However, that makes it necessary to pay special attention to the organisation of these open spaces. All the factors concerning planning should be taken into account and evaluated at the planning stage of the urban open spaces. Neglecting one or a few of the factors which should be scrutinized in the planning process may cause significantly great amount of physical and moral damages. The problems that people face in their daily life are continuously increasing, and people's resistance to these problems is gradually decreasing. In the course of a lifetime, accumulation of the stress of life occurring in an individual manifests itself in that accumulates on an individual who express' that in the forms of grudge, anger, jealousy, hatred, longing, love, etc. Traces of some of these feelings can easily been seen when looked around, especially at the public spaces. The theme of this paper is the physical dimension of the problem of vandalism of which social and physical reflections concern the city and the city dwellers depending on the location factors of city dwellers and amenities a city provides.
\end{abstract}

Key words: Vandalism, physical quality of environment, location factor, urban aesthetics.

\section{INTRODUCTION}

Vandalism is considered as a problem that stems from disturbances in urban environments. Vandalism may be related to the socio-economic conditions of individuals who have low level of education and lack of urban management in public spaces. Vandalism, which is one of the ways of expressing a person's psychological and social uneasiness, can not be completely prevented (Coffield 1991; Cohen, 1995; Philips, 1996; Ferrell and Sanders, 1995; Stollard, 1991). However, designers can minimise the occurrences and outcomes of vandalism by taking human behaviors into account and setting positive precautions.

${ }^{{ }^{*} C o r r e s p o n d i n g ~ a u t h o r . ~ E-m a i l: ~ a y a v u z 75 @ ~}$ hotmail.com. Tel: +90 533 5189052. Fax: +90 4623775588.
With its social and physical reflections, the problem of vandalism causes material losses and decreases in environmental qualities affecting citizens morally (URL1, URL2). Due to vandalism, while the amount and usage capacity of well qualified public spaces and social interactions are decreasing, dissatisfaction of their users is increasing.

This paper is concerned with the effects of locational factors on vandalism of the public open spaces and factors that need to be taken into account when designing such spaces to minimize vandalism. In order to assess the effects of locational factors on vandalism, three parks in Trabzon city were chosen and the amount of damage to the park furniture was evaluated in connection with the locational factors. Our results indicate a relationship between the locational factors and the vandalism. Thus, in designing open spaces, the 

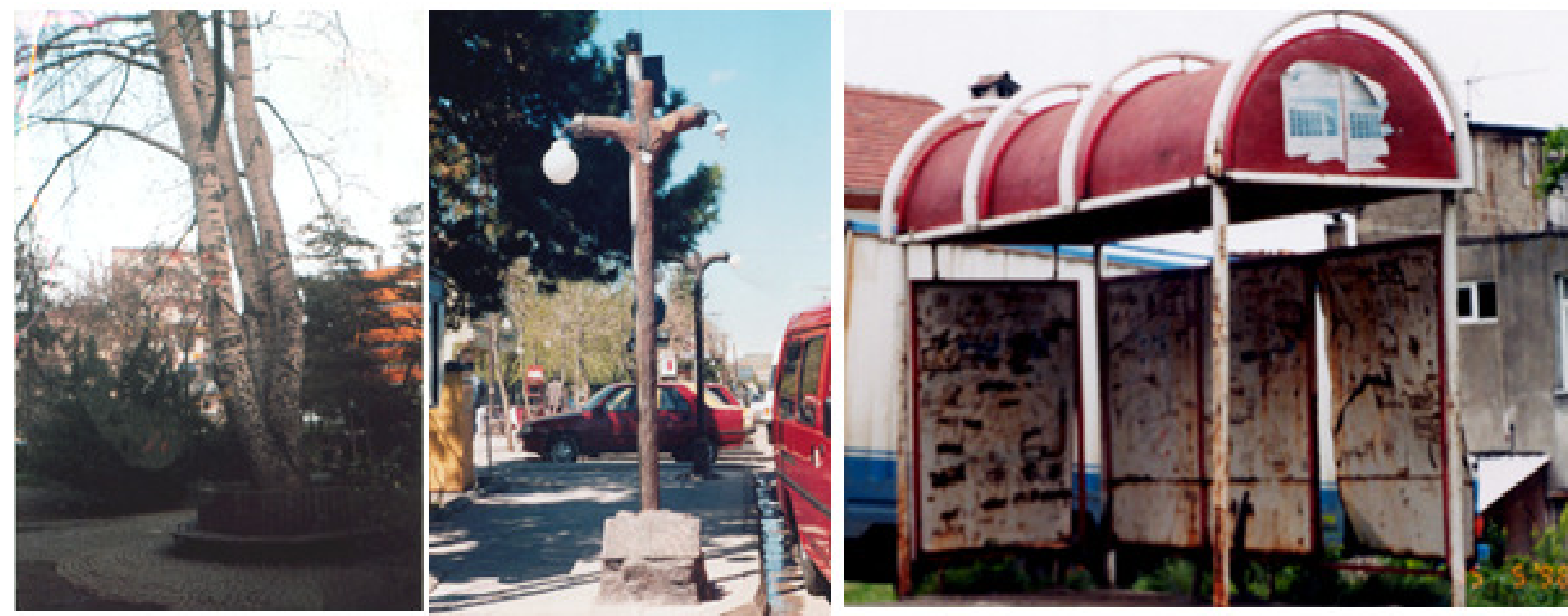

Figure 1. Some examples of vandalism.

importance of the locational factors on vandalism must be taken into consideration by designers.

\section{Vandalism in public spaces}

Vandalism is one of the general dangers in the public realm, especially in public open spaces (Lynch, 1971). Studies carried out for many years in disciplines such as psychology, sociology, criminology, linguistics and more recently in design, showed that vandalism has made significant destructions in public spaces and has been considered to be a danger for the cities and people who live in them. Stanley Cohen, a psychosocial researcher, describes vandalism as illegally destroying the goods belonging to someone else or spoiling their appearances (Ward, 1973). Acts of vandalism can be seen at various places as shown in Figure 1 (Yildirim, 2000).

It can be concluded from the descriptions made by various disciplines that vandalism is any activity of deliberately damaging or destroying things and the conspicuous defacement or destruction of a structure or a symbol, public furniture; which turns out to be, against the will of the owner/governing body. Vandalism can be cited as "official vandalism, vandalism as crime and vandalism as art" (URL3). As for the physical reflections or incidences of vandalism, they are seen in many districts in different forms in the city of Trabzon, just as they are in every country and every city.

\section{MATERIALS AND METHODS}

The problem of vandalism reduces the quality of parks which may discourage people to visit them. Parks provide people chances for relaxation, recreation, entertainment, social interaction etc. Observations made in the public spaces in Trabzon revealed that because of incidences of vandalism some places and street furniture are rendered useless. Demands of the users of these places which are damaged in some degree cannot be supplied properly and timely. While the users try to get rid of some of the stress of life, relax or use these places for any other reason, they may encounter some unexpected problems. Users walking through in public places where the illuminating elements such as lampposts are destroyed or are out of order may pose risks of robbery, assault or crime. As Truman also put it, vandalism comprises very simple activities, but when they are handled together, they seem to make up a very serious problem (Poyner, 1983).

In this research, only the incidences of vandalism occurring in some city parks/open spaces are investigated, and location factors of amenities are assessed The other factors that are considered to be effective in the occurrence of vandalism, such as user's income level, age, sex, education, mood etc, are not included in this study. The three parks chosen as case study fields are namely, Ahmet Sener Park, Adnan Kahveci Park, and 100. Yil Park (100th Anniversary Park).

Field observation was chosen as the method to determine the incidences of vandalism in parks and public spaces, (Ward, 1973; Goldstein, 1996; Samdahl, 1985, Yavuz and Kuloğlu, 2010).

Initially, observations were made weekly to determine the possible incidences of vandalism in the three parks mentioned earlier. Since our weekly observations show no significant incidences of vandalism, following observations were carried out monthly for fourteen months. Traces of destructions were determined by the method of photography. A photograph of each park was property taken every month and compared to the previous month's photograph to determine the occurrence of any new damage. The results of occurrences of incidences of vandalism on park furniture within this period have been recorded and evaluated by locations of properties and the parks. However, the reason of vandalism in urban open spaces is not considered in the frame of this study. The study is important as it explains vandalism in open urban areas and its negative effects on city quality. Plus, it leads 
Table 1. Number of destructed park furniture at the end of the study period.

\begin{tabular}{lccc}
\hline Furniture & Ahmet Sener park & Adnan Kahveci park & 100. Yil park \\
\hline Total number of benches & 30 & 76 & 51 \\
The number of destroyed benches & 29 & 70 & 18 \\
Total number of illumination & 41 & 112 & 57 \\
The number of damaged illumination & 17 & 30 & 11 \\
Sunshade elements & 5 & 6 & 4 \\
The number of damaged sunshade elements & 5 & 2 & 4 \\
Total number of picnic tables & 0 & 0 & 11 \\
The number of damaged picnic tables & 0 & 0 & 11 \\
\hline
\end{tabular}

Table 2. The presence of damaged furniture by month.

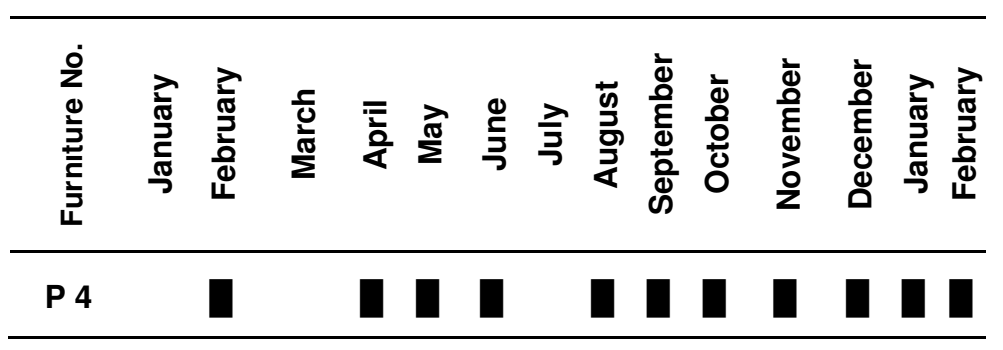

public spaces planning in the right direction.

\section{Observed destructions}

After investigating the locations of park furniture and materials in Ahmet Sener Park, Adnan Kahveci Park and 100. Yil Park, the furniture has been marked on site maps to assess the importance of their local state in the occurrence of the incidences of vandalism.

Observations have been focused on the benches, lighting elements such as lamp-posts, sunshade elements and picnic tables. Types of the park furniture, their current conditions, and relative positions have been used as the object of observation.

The amounts of destruction have not been taken into consideration during the observations; it has rather been checked whether a new destruction has been made in respect of the previous observations. Table 1 shows the distribution and the conditions of park elements.

\section{RESULTS}

\section{Assessment of the investigations}

Before and after each observation every month, the destructions and the types of damages which have been made are recorded in tables and maps (Table 1). In each monthly observation, the damages observed were represented with a circle on the map which shows the location of concentration points of damages and destroyed pieces of the furniture that show if there are any differences by locations according to the others. There is no relationship between the size of circle and the one of damage that circles represent.

Each ring indicates that there is a destruction/damage observed in that month. If there is an additional destruction observed in the following month, a new ring is added to the same location on the map. In short, rings show the number of months that the part equipment was damaged. For instance, during 14 month observation period, if a furniture was damaged in February, April, May, June, August, September, October, November, December, January and February, there will be 11 rings around that furniture in the plan (Table 2).

\section{Distribution of damages on the furniture by their locations}

With this study, in what parts the destructions are the most common has been determined. The destroyed furniture was evaluated regarding not only their relations depending on their location according to each others, but also the relations with their absolute location in the research area and vandalism activities. To do this, the furniture in Ahmet Sener Park (Figure 2), in Adnan Kahveci Park (Figure 3) and in 100. Yil Park (Figure 4) was observed and the recorded destructions were put on the plans. 


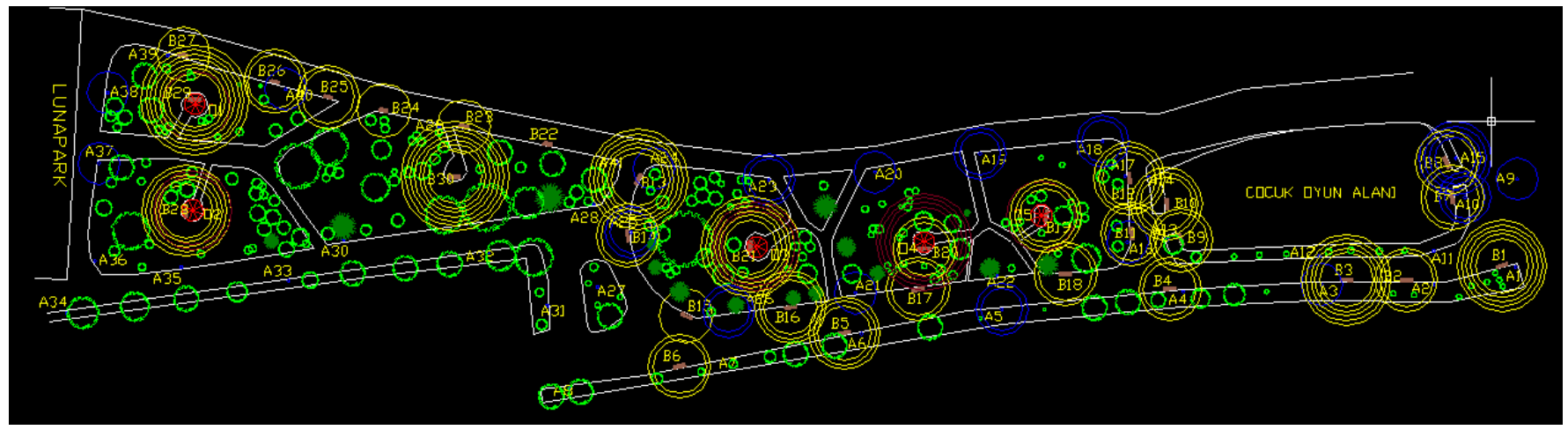

Number of the months in which damages were found at the benches

- Number of the months in which damages were found at the elements under sunlight

Number of the months in which damages were found at the elements of covering

Figure 2. Ahmet Sener park.

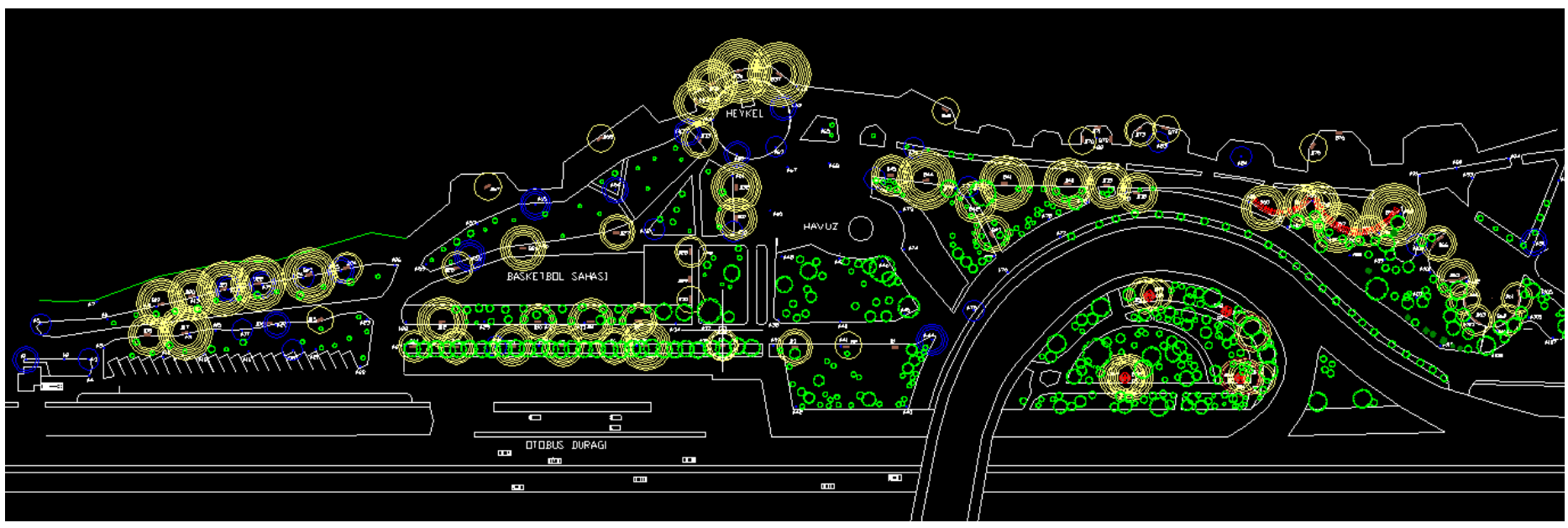

\section{Number of the months in which damages were found at the benches}

- Number of the months in which damages were found at the elements under sunlight

Number of the months in which damages were found at the elements of covering

Figure 3. Adnan Kahveci park.

\section{DISCUSSION}

\section{Distribution of damages given to benches by their location}

In Ahmet Sener Park, the benches numbered B13, B20, B21, B28, B29 and B30, located in semi-closed places surrounded by either partly or fully covered dense plants, have been damaged more than the others. This may be due to the fact that benches are situated on the secondary roads which are far from the road junctions and remain out of the sight of the other park users. The lack of control by the park management creates this kind of non-defensible areas and consequently motivates vandalism (Ward, 1973).

When Adnan Kahveci Park is surveyed, it seems that the number of damaged benches in the district facing the sea is very great in proportion to the other in consideration of the imaginary division of the park in the directions of east and west. It attracts attention that the damaged benches are close to each other from the location point of view (Figure 3). This situation proves 


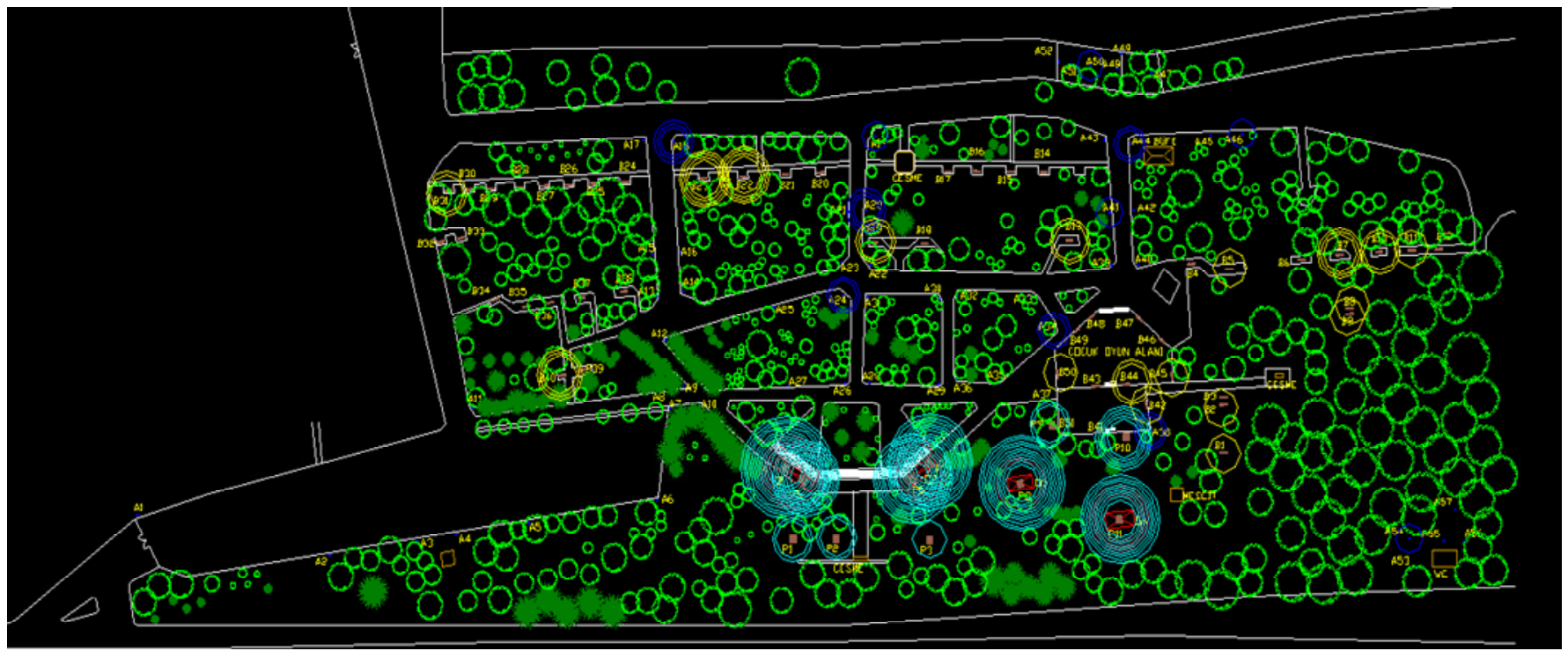

Number of the months in which damages were found at the benches

O Number of the months in which damages were found at the elements under sunlight

Number of the months in which damages were found at the elements of covering

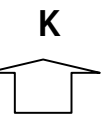

Figure 4. 100. Yil park.

that first damages given are likely to cause a triggering reason for vandalism (Poyner, 1983; Underwood, 1980; URL4). The same conclusion refers to 100 . Yil Park, as well.

\section{Distribution of damage of the elements on illumination materials by their locations}

In Ahmet Sener Park, damaged elements of illumination are densely found around the centre of the park. The broken elements of illumination that are not repaired afterwards increase the possibility of vandalism on others around it. The damages observed on the neighbouring illumination elements, A25, A26, A18, A10, A9 and A24, support the possibility that damage at an element causes damages on the elements located nearby (Underwood, 1980).

Visibility of the lighting and illuminating elements numbered A30, A31, A32, A33, A34 and A35 are screened by groups of shrubs which appear to decrease the incidences of vandalism, especially in the seasons when these plants have leaves. Similar observations were made in Adnan Kahveci Park. The illumination elements located in poorly planted areas were more often targets for vandalism while illumination elements located in shrubs and bushes numbered A27, A28, A29, A30, $\mathrm{A} 31, \mathrm{~A} 32, \mathrm{~A} 33, \mathrm{~A} 34, \mathrm{~A} 35, \mathrm{~A} 36$ and $\mathrm{A37}$, were not damaged as much (Figure 2). Some illumination elements numbered A17, A18, A20, A21, A22, A24, A25, A50, A53 and A54, located among bushes and short trees, were also vandalized.

\section{Distribution of damages on sunshade elements}

In Ahmet Sener Park, sunshade elements are situated on secondary roads. In addition, they have been partially screened by plant groups that can be seen from the main roads in the park. Although there are many different sunshade elements in different locations in this park, that those conditions are considered to be effective one by one in damaging these elements. Sunshade element Ö4 that is out of control because of the dense plantation (Figure 1) is damaged more in comparison to others which have similar location with the other elements. Damages have also been observed at the sunshade elements under the flyover in Adnan Kahveci Park (Figure 2). This area planted with tall plants is used more occasionally than others, in which the furniture is much exposed to vandalism.

In 100. Yil Park, in which sunshade elements already exist are most exposed to vandalism because their visibility from the secondary roads has been partly screened by plant groups and are obscured visual controls (Figure 4). 


\section{Distribution of picnic tables according to their locations}

Our observations showed that picnic tables at 100 . Yil Park have been the targets of vandalism most. Especially, the picnic tables located under the sunshade elements have been damaged more than the ones located in the open area (Figure 3). Furniture in the semicovered places is more likely to be the target for the incidences of vandalism.

\section{Conclusions}

As a result "location factor" has been identified as an important factor in cases of vandalism in public places.

The powerful interactions among the users of urban furniture, location and visual control appear to be important determinants of space quality in public area planning. All these factors that affect vandalism should be considered in designing open public places in order to minimize the occurrence of vandalism.

In public spaces planning, some detailed analyses should be done for the furniture choosing. Comfort, climatic characteristics, scenic direction, material, colour, durability etc. are so important while location of the furniture should also be decided and they should be put in the parts that the users can see each others easily. It is found that the furniture for which visual comfort is provided is under less vandalism pressure comparing with the rest.

\section{REFERENCES}

Coffield F (1991). Vandalism \& Graffiti. The State of the Art London. Calouste Gulbenkian Foundation.

Cohen AK (1995). Delinquent Boys: The Culture of the Gang. The Free Press. New York. A Division of Macmillan Publishing Co. Inc.

Ferrell J, Sanders CR (1995). Cultural Criminology. Boston. Northeastern University Press.

Goldstein AP (1996). The Psychology of Vandalism. New York. Plenum Press.

Lynch K (1971). Site Planning, Second Edition. Cambridge. Massachusetts Institute of Technology Press.

Philips LE (1996). Parks: Design and Management. New York. McGraw Hill Book Co.

Poyner B (1983). Design Against Crime-Beyond Defensible Space. Cambridge. Butterworths Litho Preparation Department Printed in Great Britain at the University Press.

Samdahl DM, Christensen HH (1985). Environmental Cues and Vandalism. An Exploratory Study of Picnic Table Carving. Environ. Behav., 17: 445-448.

Stollard P (1991). Crime Prevention Through Housing Design. First Edition. London. An Imprint of Chapman \& Hall.

Underwood G (1980). Vandalism. Archit.' J. 171 (24): 1171-1174.

URL 1: http://www.infowest.com/business/n/ngin/impact.gif.

URL 2: http://www.nwatch.org.uk/howtotac.htm.

URL 3: Vandalism, http://en.wikipedia.org/wiki/Vandalism.

URL 4: http://www.tas.gov.au/

Ward C (1973).Vandalism. First Published. London.The Architectural Press.

Yavuz A, Kuloğlu N (2010). An experimental study on vandalism: Trabzon Parks. Sci. Res. Essays, 5(17): 2463-2471.

Yildirim A (2000). Vandalism in Public Spaces. Master Thesis. KTU. Trabzon. 